\title{
Representations of Gender-Diverse Characters in Adventure Time and Steven Universe
}

\author{
Abigail S. Walsh \\ Correspondence: Abigail S. Walsh, Department of Psychology, University of California Santa Cruz, 1156 High Street, \\ Santa Cruz, CA 95066. E-mail: abwalsh@ucsc.edu
}

Received: Oct. 18, 2020

doi:10.11114/smc.v8i2.5048
Accepted: Nov. 12, $2020 \quad$ Online Published: Nov. 16, 2020

URL: https://doi.org/10.11114/smc.v8i2.5048

\begin{abstract}
Television is a strong educational and socializing agent for children. Watching television can teach children appropriate language and vocabulary to use, as well as the social norms about gender behaviors or activities. Previous research on gender representations in children's television has been limited to studying male and female characters because children's programming has historically presented audiences with cisgender characters (e.g., boy and girls). Recently, television shows aimed at children have provided audiences with nonbinary and gender-diverse characters. This study is the first exploratory content analysis, to my knowledge, to examine the portrayal and representation of nonbinary and genderdiverse characters in children's television. The current study examined the gender-neutral pronoun and gendered language use toward nonbinary and gender-diverse characters, as well as the portrayal of these characters as leaders, and with special skills in Adventure Time and Steven Universe. Overall, nonbinary and gender-diverse characters were portrayed as strong, positive, characters, and were represented similarly to their cisgender counterparts. This represents a promising shift toward more inclusive and equitable television representation, which may lead to the acceptance and appropriate use of gender-neutral pronouns toward peers by cisgender children, and the feeling of visibility and validation by nonbinary children. Future research should examine the impacts of these characters on viewers.

RELEVANCE STATEMENT: As children's television becomes more diverse it has the potential to positively impact the lives of cisgender (e.g., boys and girls) and nonbinary children. Because television has the potential to influence young children, gender-diverse representations in children's television may lead to children developing more accepting attitudes and behaviors toward nonbinary peers.
\end{abstract}

Keywords: gender, children's television, media, nonbinary

\section{Introduction}

Given the historical prevalence and persistence of cisgender stereotypes of boys and girls, men and women, in children's television (See Thompson \& Zerbinos, 1995; Ward \& Aubrey, 2017), it is important to analyze how these stereotypes may or may not be changing with new and innovative programming. New shows may be considered innovative for their upfront and explicit inclusion and portrayal of nonbinary characters (Flowerday, 2014; Clark, 2017), who explicitly identify as neither male nor female. Adventure Time and Steven Universe are two such examples of these children's shows. The nonbinary characters in these are not simply presented as ambiguous in gender characteristics or presentation; each nonbinary character holds an explicit identity outside of the gender binary. These shows also take different approaches to nonbinary and gender diverse themes. Fans of these shows consider the representation of these nonbinary characters to be overwhelmingly positive, nuanced, and dynamic (Clark, 2017; Kohn, 2013).

The presence of nonbinary and gender-diverse characters in children's programming may lead to positive developmental outcomes. For example, research has shown that positive representation of outgroup members may lead children toward more positive opinions and beliefs about others (Browne Graves, 1999; Lovelace et al., 1994; Ward \& Aubrey, 2017). In this case, positive representations of nonbinary characters may lead cisgender children toward positive opinions of nonbinary people. Additionally, positive representations have led to self-acceptance and higher self-esteem for those with marginalized identities who are less likely to be portrayed positively in children's media (Martins \& Harrison, 2012; Ward \& Aubrey, 2017). In the case of nonbinary and gender-diverse characters, this may mean that cisgender children, those who identify with the sex they were assigned at birth, who watch these shows may show more acceptance of others who hold marginalized identities. At the same time, these shows may provide nonbinary and gender minority youth with 
examples of characters with whom they can connect, relate, and identify. For research to examine these potential benefits of nonbinary characters in children's television, the quality of these representations must first be identified. The current study sought to identify the portrayal of nonbinary characters who are portrayed as nonhuman (in Adventure Time) or humanoid (in Steven Universe). This research examined the use of gender-neutral language, leadership, and the use of special skills. Previous research on these variables, highlighting work in cisgender characters, is discussed below. Operational definitions for these variables are provided in the method section.

\subsection{Gender in Children's Television}

Most of children's television tends to portray gender in rigid, stereotypical, and cis-normative ways, including portraying male and female characters differently (Ward \& Aubrey, 2017). Male characters tend to be portrayed as strong, aggressive, and assertive, while female characters ask more questions, ask for help, and are more concerned with their appearance (Aubrey \& Harrison, 2004; Signorielli, 2012; Ward \& Aubrey, 2017). There exist many persistent gender-stereotyped representations in children's television. Previous research relevant to the current study is discussed below.

Little research has started to explore the role of gendered voices, language, and pronouns on children's television. One such study found that television advertisements aimed at children utilized different language (e.g., action verbs, power words) depending on whether the advertisement was about a boy-typed or girl-typed toy (Johnson \& Young, 2002). Despite some research on gendered language and traits, this research has been limited in its analysis due to the lack of gender diversity in children's television programming. Perhaps it was previously unnecessary to explore gendered language and gendered pronouns in children's television because of the overwhelming presence of characters who identity within the gender binary.

Male and female characters are also portrayed differently in terms of their bodies in children's media. Female characters are more likely to be portrayed as hyper-thin (Götz \& Lemish, 2012) and concerned or preoccupied with their appearance than are male characters (Thompson \& Zerbinos, 1995). The differential emphasis on appearance for female and male characters may influence how children view their own appearance and the self-socialization of their gender-typed appearance (Halim \& Lindner, 2013; Halim et al., 2014).

Previous research has also found that children's media may be perpetuating ideas about nonhuman characters and their body types. For example, research has found that nonhuman characters (animals, robots, etc.) tend to be portrayed as male characters (Elias et al., 2017; Jones, 2011; Walsh \& Leaper, 2020). Whether intentional or not, children's television sends the message that femaleness, girlhood and womanhood, are restricted, confined, to a particular female form. The male form is in some ways a genderless default. Women and girls in children's television need to be recognizable by their bodies, clothes, hair, accessories (Walsh $\&$ Leaper, 2020). It is necessary to identify how different nonbinary characters are portrayed when place in human or nonhuman forms.

Male characters are also more likely to be portrayed in prominent or main leadership roles and as dominant and powerful characters (Ahmed \& Abdul Wahab, 2014; Leaper et al., 2002; Murnen et al., 2016; Thompson \& Zerbinos, 1995). Even when male and female characters are portrayed engaging in similar behaviors they are portrayed differently, including their screen and speaking time (Geena Davis Institute on Gender in Media, 2016). Additionally, male characters are more likely to be portrayed in a positive light when they take charge and direct others' actions, while female characters tend to be portrayed negatively for these behaviors - they are seen as bossy (Aubrey \& Harrison, 2004; Signorielli, 2012). Children may incorporate these gender-typed representations of appearance and behavior into their gender schemas of what is appropriate for themselves and others (Bussey \& Bandura, 1999; Martin \& Halverson, 1981). These potential impacts are discussed below.

\subsection{Learning from Television}

Television can impact children's own gender development, as well as their understanding and beliefs about gendered others (Bussey \& Bandura, 1999; Martin \& Halverson, 1981). Children who watch media with counter-stereotypical gender representations, for example, are more likely to endorse egalitarian attitudes and less likely to engage in rigid gender-typed behaviors (Ward \& Aubrey, 2017). Additionally, evidence suggests that diverse and counter-stereotypical gender representations may make marginalized groups (e.g., girls) feel more validated, empowered, and important (Fisch, 2004; Ryan, 2010). It is likely that positive representations of nonbinary characters would have similar effects for children who identity outside of the gender binary.

Children also have a great capacity to learn vocabulary and gendered language from the television they watch (Fisch, 2004). Previous research has established that young children learn what words and vocabulary to use from watching television programs (Rice et al., 1990) and that television can serve to facilitate children's language acquisition (Lemish \& Rice, 1986; Linebarger \& Walker, 2005). Children may also learn what language is specifically related to boys and girls when language is used differentially. For example, children can identify gender differences in the language used in 
popular cartoons and may form stereotyped opinions based on these differences in language use (Stamou et al., 2015).

Research has explored the impact of watching gender-stereotypes and sexualized bodies on both boys and girls. For example, research has shown that children internalize information about bodies, sexualize and objectify themselves and others based on media exposure (Fredrickson \& Roberts, 1997; Trekels \& Eggermont, 2017). These kinds of beliefs are associated with lower expectations of girls and women's capabilities, and negative mental health outcomes (Grabe $\&$ Hyde, 2009; Tiggemann \& Slater, 2015). Children view people's gender through their bodily representation and create expectations for what they or others are capable of. Research has yet to examine if this persists for nonbinary characters dependent on their presentation as nonhuman, or humanoid and gendered.

Additionally, research has examined the role of television on children's ideas about leadership. Previous research has found that stereotypical representations are associated with stereotypical expectations. For example, gender-stereotyped representations have been linked to children's expectations about who can and should perform different occupations (Nathanson et al., 2002; Puchner et al., 2015). However, research has also shown that counter stereotypical representations may be related to more positive attitudes and expectations. For example, research has found that the presence of strong female characters in television and film is related to lower endorsement of negative attitudes about women (Ferguson, 2012).

Previous research on children's media has identified gender-stereotyped representations and the effects of consuming them on children's beliefs, expectations, and behavior. However, most previous research has reflected on cisgender male and female characters. Gender diversity and visibility in children's media is becoming increasingly relevant as more and more children are identifying in gender-diverse ways (e.g., transgender, nonbinary) (Brooks, 2017; Olson \& Gülgöz, 2018). Until recently, children's television did not represent characters that reflect the identities and experiences of these gender-diverse children. The current study sought to add to the existing literature by identifying the gendered language used toward and in reference to gender-diverse characters in children's cartoon programming and the ways in which gender-diverse characters are represented as leaders or with special skills.

\subsection{Current Study}

The current study consisted of an exploratory content analysis on the use of gendered language toward and the portrayal of nonbinary and gender-diverse characters in Adventure Time and Steven Universe. These shows present a unique opportunity because they present queer and gender-diverse characters specifically for child audiences. It is important to note that these shows are not niche or obscure television shows. These shows have high television ratings and a large fan following (Clark, 2017; Kohn, 2013). In the current study, a content analysis was conducted to examine the use of gendered and gender-neutral language toward nonbinary and gender-diverse characters. The analysis also examined the representation of these characters as leaders and characters with special and unique powers or skills. To my knowledge this is the first content analysis of gender-typed and gender-neutral language and character representations of genderdiverse characters in children's television. This investigation sought to explore 1) how characters are using gendered and gender-neutral language toward and in reference to nonbinary characters, 2) how nonbinary characters are depicted in leadership roles, 3) how nonbinary characters are depicted with special skills, and 4) if these representations differ based on the show. Given that this is the first study to examine these questions, analyses were exploratory, to establish patterns of representation for nonbinary and gender-diverse characters in children's programming.

\subsubsection{Television Shows}

Adventure Time and Steven Universe both air on Cartoon Network and are specifically created to children. Adventure Time is a post-apocalyptic fantasy series in which Finn, the last human, and Jake, a magical shape-shifting dog, go on adventures with their friends. BMO is a computerized robot, friend, and roommate of Finn and Jake. BMO is a regular character on the show and explicitly does not have a gender (Olson, 2013).

Steven Universe is a fantasy series in which Steven, a half-human half gem, fights alongside the Crystal Gems to protect planet earth. The Crystal Gems are aliens who come from a planet with no conception of gender. All of the gems identify as nonbinary, or genderless, but many of them use she/her pronouns (Polo, 2016). Gems also are able fuse together to become a larger more powerful gem. These fusions are also explicitly nonbinary in gender identity (Rude, 2018).

These shows were chosen because they have important similarities and differences that provide interesting points of comparison. These shows are similar in that they 1) feature nonbinary characters, 2) are created for children, 3) are animated in similar styles, and 4) air on the same network. However, these shows are also different in that in Adventure Time 1) nonbinary characters are computers/nonhumanoid, and 2) there are no explicit themes in the show's content around gender identity or gender politics that are consistently presented, whereas in Steven Universe 1) nonbinary characters are humanoid gem characters, usually presenting in a feminized form and, 2) there are multiple explicit themes around gender identity and gender politics throughout the entire series. By comparing how these characters are portrayed 
and talked to or about within the shows it is possible to examine the role of presence of nonbinary-identified character versus presence of nonbinary-identified characters with explicit and consistent gender-theming.

\section{Method}

\subsection{Selection of Television Episodes}

Thirty episodes each of Adventure Time and Steven Universe were analyzed in this study. Each episode was provided a number for the season and episode number. For example, episode 17 from season 5 was given the number 517. Shows were then chosen at random using Google's random number generator. This resulted in at least one episode, from each season of each show being included in the content analysis, with a total of 60 complete episodes coded in the present study.

\subsection{Coding}

Each episode was coded for 1) gendered language use toward nonbinary characters, 2) the leadership and 3) special skills presented by nonbinary characters. Gendered language use was conceptualized in two ways. First, coders counted the frequency of masculine (e.g. he/him), feminine (e.g., she/her) and gender-neutral (e.g., they/them) pronouns that were used in reference to nonbinary characters. Second, coders counted the frequency of male-typed gendered terms (e.g., bro) and female-typed gendered terms (e.g., m'lady) used in reference to nonbinary characters. Leadership was conceptualized as any time a character was taking charge, directing others' behavior, or engaging in agentic problem solving (e.g., deciding the course of action for a quest). Special skills were considered to be any abilities above and beyond what was typical or normative in each show (e.g., magical powers, fusion).

Each of these variables were counted for frequency of occurrence within an episode for each individual character. Characters behaviors were then summed across episodes for a total frequency count of the number of instances of each variable for each show. These totals were then converted into proportion scores based on the number of episodes each character was in. This choice was made to ensure that characters' scores for each variable were not influenced by their presence in more episodes than those of other characters.

Two research assistants coded 10 randomly selected episodes of Adventure Time and 10 randomly selected episodes of Steven Universe that were not included in the final analyses, to establish inter-coder reliability. This process was repeated three times, at which point the coefficient for each variable was considered satisfactory. Inter-coder reliability was calculated using intra-class correlations (ICC) (Landers, 2015). Good reliability is reflected when ICC values are at least 0.75 , and excellent reliability is indicated when ICC values exceed 0.90 (Koo \& $\mathrm{Li}, 2016$ ). The ICC values for each variable reached a minimum value of 0.91 . After each research assistant had coded 15 episodes to be included in the final data, a reliability check was conducted. Research assistants each coded the same 5 randomly selected episodes of Adventure Time and the same 5 randomly selected episodes of Steven Universe. As these 10 episodes were analyzed for the purpose of a reliability check, they were not included in the final analysis. During the reliability check for these 10 episodes the ICC values for each variable reached a minimum of 0.88 . After reassessing reliability, each coder completed coding for the last 15 episodes. Each research assistant coded 15 episodes of Adventure Time and 15 episodes of Steven Universe in total.

\section{Results}

A 2x2 ANOVA was conducted to explore the potential differences between the representation of gender (cisgender and nonbinary characters) in each show (Adventure Time and Steven Universe) for each variable. Descriptive statistics for each variable by gender and show can be found in Table 1. Results are presented below.

Table 1. Descriptive statistics for each dependent variable by gender and show

\begin{tabular}{lcccc}
\hline Television show & \multicolumn{2}{c}{ Adventure Time } & \multicolumn{2}{c}{ Steven Universe } \\
\hline & Cisgender & Nonbinary & Cisgender & Nonbinary \\
& Characters & Characters & Characters & Characters \\
Male Pronouns & $.11(.37)$ & $.04(.10)$ & $.48(1.00)$ & $.14(.28)$ \\
Female Pronouns & $.07(.31)$ & $.04(.10)$ & $.55(1.48)$ & $.40(.64)$ \\
They/Them Pronouns & $.00(.00)$ & $.01(.09)$ & $.11(.04)$ & $.05(.18)$ \\
Male Terms & $.22(.80)$ & $1.19(2.45)$ & $.44(1.12)$ & $.16(.50)$ \\
Female Terms & $.06(.14)$ & $.03(.08)$ & $.11(.28)$ & $.02(.05)$ \\
Leadership & $.11(.31)$ & $3.33(5.72)$ & $1.10(2.29)$ & $.55(1.30)$ \\
Special Skills & $.18(.63)$ & $.45(1.09)$ & $.92(2.02)$ & $1.10(2.34)$ \\
\hline
\end{tabular}

\subsection{Gendered Language Used Toward Nonbinary Characters}

The data were first analyzed for the use of masculine, feminine, and gender-neutral pronouns toward nonbinary characters. 
Results showed no significant main effects for gender, $F(1,1)=2.04, p=.157$, show, $F(1,1)=2.78, p=.099$, or interactions of gender and show, $F(1,1)=.91, p=.343$ for the use of male pronouns toward nonbinary characters. Results showed a significant main effect for show, $F(1,1)=4.73, p=.032$, in that characters were more apt to use female pronouns toward nonbinary characters in Steven Universe than in Adventure Time. This result is not surprising given that many characters who identify as nonbinary in Steven Universe, chose to use female pronouns (Polo, 2016). Results showed no significant main effect of gender, $F(1,1)=.21, p=.648$, or interactions of gender and show $F(1,1)=.09, p=.766$, for the use of female pronouns toward nonbinary characters. Results showed no significant main effects of gender, $F(1,1)=2.34$, $p=.129$, show, $F(1,1)=1.02, p=.314$, or interactions of gender and show, $F(1,1)=1.02, p=.314$ for the use of neutral (they/them) pronouns toward nonbinary characters. This finding, though a null result, is especially representative of equity and inclusion in these shows.

The data were also analyzed for the use of male- and female-typed terms. Results showed no significant main effects for gender, $F(1,1)=2.54, p=.114$, show, $F(1,1)=1.80, p=.183$, for the use of male-typed terms toward nonbinary characters. However, a statistically significant gender by show interaction was observed for male-typed terms, $F(1,1)=5.98, p=.016$, in that cisgender characters in Steven Universe used male terms toward nonbinary characters, while nonbinary characters in Adventure Time used male terms toward nonbinary characters. Results showed no significant main effects for gender, $F(1,1)=1.77, p=.187$, show, $F(1,1)=.18, p=.674$, or interactions of gender and show, $F(1,1)=.61, p=.437$ for the use of female terms toward nonbinary characters.

\subsection{Leadership}

Leadership was analyzed to examine if cisgender and nonbinary characters were portrayed in different ways in either show. Results showed a main effect of gender, $F(1,1)=8.65, p=.004$, and a main effect of show, $F(1,1)=3.93, p=.005$. A gender by show interaction was also observed, $F(1,1)=17.22, p<.000$, in that nonbinary characters were more often portrayed as leaders in Adventure Time and cisgender characters were more likely to be portrayed as leaders in Steven Universe.

\subsection{Special Skills}

Special skills were analyzed to examine if cisgender and nonbinary characters were portrayed in different ways in either show. Results showed no significant main effects for gender, $F(1,1)=.35, p=.556$, or interactions of gender and show, $F(1,1)=.01, p=.909$ for the demonstration of special skills. There was a marginally statistically significant difference by show, $F(1,1)=3.29, p=.072$, in that characters in Steven Universe were marginally more likely to be portrayed using special skills.

\section{Discussion}

This study sought to examine and identify ways in which nonbinary characters are treated and portrayed in two cartoon shows created for children. These shows differed in the types of gender-diverse messaging presented to audiences. Adventure Time presented viewers with nonhuman nonbinary characters without explicit messaging about gender. On the other hand, Steven Universe presented viewers with humanoid nonbinary characters and consistent messaging about gender-diverse themes (Rude, 2018). The question of representation was addressed by conducting a content analysis of the gendered language used toward nonbinary characters, representation of leadership, and of special skills presented in 30 randomly selected episodes of each show. The results and their implications are discussed below.

\subsection{Gendered Language Used Toward Nonbinary Characters}

No significant differences were observed for how characters in Adventure Time or Steven Universe used masculine pronouns toward nonbinary characters. A difference was observed for feminine pronouns, in that characters were more likely to use the terms she/her in reference to nonbinary characters in Steven Universe than in Adventure Time. This difference, however, is not surprising. The gem characters in Steven Universe explicitly identify outside of the gender binary, but many of them use feminine pronouns on Earth. Rebecca Sugar, the creator of Steven Universe, points to her own experience as a nonbinary person who uses feminine pronouns as the rationale for this choice (Clark, 2017; Polo, 2016; Rude, 2018). The use of feminine pronouns for nonbinary characters offers viewers nuance in understanding the identities and pronoun preferences of members of the nonbinary community.

There were also no differences observed in the use of gender-neutral (e.g., they/them) pronouns for nonbinary characters. It is important to note that the means for gender-neutral language use were low; it is likely that these characters were addressed in other ways. For example, it has been noted that these characters are often referred to by proper name and by multiple pronouns, sometimes being referred to as "he" and sometimes being referred to as "she" (Clark, 2017). It is also essential to recognize the importance of a null result in this context. In this case, both cisgender and nonbinary characters used gender-neutral pronouns toward nonbinary characters, regardless of the show. These characters consistently used appropriate pronouns toward nonbinary and gender diverse characters. Given that television is a powerful socializing 
agent for young children (Bussey \& Bandura, 1999; Gerbner, 1998), children who view these television shows may learn to use gender-neutral pronouns appropriately and colloquially. This practice has strong implications for making genderdiverse and nonbinary children feel included and supported in their gender identities (Markman, 2011; Olson, et al., 2016).

\subsection{Leadership}

Results showed a main effect of gender, show, and an interaction between both dimensions. It is important to note that there are more nonbinary characters in Steven Universe than in Adventure Time. It is possible that despite being presented less frequently, nonbinary characters in Adventure Time are often depicted as leaders when they are portrayed. Nonbinary characters also play a central role in the story more often in Steven Universe than in Adventure Time. It is improbable that all the characters could be depicted as leaders in each episode. Future research should examine the prominence of character roles in parsing out some of these possibilities.

The representation of nonbinary characters with leadership skills, especially in Adventure Time, is particularly promising because marginalized groups (e.g., female characters) have not always been portrayed with these kinds of leadership skills (Baker \& Raney, 2007; Götz et al., 2008; Leaper et al., 2002). This reflects well on how nonbinary characters, with similarly marginalized identities are, and can continue to be, represented in children's television. When marginalized groups are portrayed as strong characters, their presence and representation can ameliorate some negative stereotyped media effects. For example, when strong female characters are present in television and film, people are less likely to endorse negative attitudes about women (Ferguson, 2012). By depicting nonbinary and gender diverse characters as leaders, content creators position them to be validated as strong and capable characters. This may lead audiences to think more positively about members of these groups in real life.

\subsection{Special Skills}

Results showed no main effect of gender and no interaction effects between dimensions. However, results showed a marginally significant difference in that characters in Steven Universe were more likely to be depicted with special skills than were characters in Adventure Time. Though not significant, this marginal difference sheds light on the role of theming around gender politics and gender identities. It is likely there are qualitative storytelling factors about Steven Universe that allow for more showcasing of special skills than in Adventure Time. Previous research has attributed genre of show to observed gender differences (e.g., Leaper et al., 2002). However, as both shows are fantasy-genre shows, where characters have special, magical, fantastical skills, genre of show is unlikely to explain the observed difference.

It is more likely that the theming around gender and the representation of nonbinary characters as humanoid play a role in these different portrayals. Steven Universe centers queer and nonbinary characters - it does not use them merely as side characters. In fact, nonbinary characters were present in every episode of Steven Universe that was included in this study. This was not the case for nonbinary characters in Adventure Time. Perhaps by centering characters with these genderdiverse and marginalized identities it is easier to tell stories through and about these characters. By shifting the storytelling focus to these characters and their identities it may be easier to showcase their talents and skills. This may signal to children that nonbinary characters and stories about them are important and valid (Smith et al., 2016).

This difference may be due to perceptions of humanoid, and in this instance, feminine-typed bodies. Perhaps Steven Universe was more likely to represent characters with special skills because these characters were more likely to be represented as humanoid. It is possible that content creators may think more expansively on what people, rather than robots, may be capable of doing in a fantasy television show. If this is the case, it is worth noting the importance of representing female-typed nonbinary characters in this way. Historically, female and feminine-typed characters are marginalized as side characters who are more likely to appear than to engage in action (Aubrey \& Harrison, 2004; Signorielli, 2012; Ward \& Aubrey, 2017). Providing feminine-typed nonbinary characters with special skills may allow both nonbinary and female-typed children to identity with the positive traits of these characters (Hoffner, 1996; Hoffner \& Buchanan, 2009). The present analysis did not investigate gender-typed appearance. This decision was intentional, based on the differences in physical representation of nonbinary characters in each show. Since nonbinary characters in Adventure Time are not humanoid it would be difficult to draw sound comparisons between shows for this type of investigation. However, future research could examine physical and gender-typed appearance as human and humanoid nonbinary characters become more widely depicted in children's television programming.

\section{Conclusions and Future Directions}

This content analysis sought to explore the language used toward nonbinary characters, and the representation of those characters as leaders, and characters with special skills. The findings provide some exciting and promising results. This study provides evidence that in the first mainstream and highly popular (Clark, 2017; Kohn, 2013) shows for children that depict nonbinary characters, that these characters are portrayed similarly to cisgender characters. The results of the current study largely demonstrate that Steven Universe and Adventure Time rarely differ in how they portray nonbinary 
characters. Characters were also observed using appropriate language and gender pronouns toward gender-diverse characters. Additionally, these characters were portrayed in positive ways, as strong leaders, with special skills. This is a departure from traditional depictions of queer characters in children's media. Previously, gender diversity and queerness has been portrayed at best as a joke (e.g., Bugs Bunny cross-dressing) (Myers, 2012) and at worst as evil or repulsive (e.g., Urusla in The Little Mermaid) (Martinez, 2015) in children's media. This new generation of television may be paving the way for positive representations of members of these groups.

This content analysis is the first step to understanding how exposure to nonbinary characters in children's television may impact children. Before we can study the impacts of these shows on their viewers, it is essential to examine how these characters are represented. Knowing that these characters are represented in similar, positive, and equitable ways can lay the theoretical foundation for future experimental and empirical work. Future work should focus on these media effects. Researchers should examine how exposure to Adventure Time and Steven Universe may affect people's attitudes and behavior toward nonbinary and gender-nonconforming people. This future work may help identify the potential benefits of watching positive and equitable representations of nonbinary characters. Special attention should be paid to the role these representations have in the lives and attitude formation of children who consume these television shows. Evidence of these potential beneficial media portrayals can inform policymakers and content creators, which may just lead to more diverse representations of gender in children's television.

\section{References}

Ahmed, S., \& Abdul, W. J. (2014). Animation and socialization process: Gender role portrayal on Cartoon Network. Asian Social Science, 10, 44-53. https://doi.org/10.5539/ass.v10n3p44

Aubrey, J. S., \& Harrison, K. (2004). The gender-role content of children's television programs and its links to their gender-related perceptions. Media Psychology, 6, 111-146. https://doi.org/10.1207/s1532785xmep0602_1

Baker, K., \& Raney, A. A. (2007). Equally super?: Gender-role stereotyping of superheroes in children's animated programs. Mass Communication and Society, 10, 25-41. https://doi.org/10.1080/15205430709337003

Brooks, J. (2017). A new generation overthrows gender. NPR. Retrieved from https://www.npr.org/sections/healthshots/2017/05/02/526067768/a-new-generation-overthrows-gender

Browne Graves, S. (1999). Television and prejudice reduction: When does television as a vicarious experience make a difference? Journal of Social Issues, 55, 707-727. https://doi.org/10.1111/0022-4537.00143

Bussey, K., \& Bandura, A. (1999). Social cognitive theory of gender development and differentiation. Psychological Review, 106, 676-713. https://doi.org/10.1037/0033-295X.106.4.676

Clark, H. (2017). "My lesbian space rock show": Representations of intersecting identities in Steven Universe (Masters thesis). Humboldt State University, Arcata, CA.

Elias, N., Sulkin, I., \& Lemish, D. (2017). Gender segregation on BabyTV.: Old-time stereotypes for the very young. In D. Lemish \& M. Götz (Eds.) Beyond the stereotypes? Images of boys and girls, and their consequences (pp. 95-104). Göteborg: Nordicom.

Ferguson, C. J. (2012). Positive female role-models eliminate negative effects of sexually violent media. Journal of Communication, 62, 888-899. https://doi.org/10.1111/j.1460-2466.2012.01666.x

Fisch, S. M. (2004). Children's learning from educational television: Sesame Street and beyond Mahwah, NJ: Erlbaum.

Flowerday, K. (2014). Learning to read (gender): Children's animation and the new heterosexism. Anthós, 6, 73-91. https://doi.org/10.15760/anthos.2014.73

Fredrickson, B. L., \& Roberts, T. (1997). Objectification theory: Toward understanding women's lived experiences and mental health risks. Psychology of Women Quarterly, 21, 173-206. https://doi.org/10.1111/j.14716402.1997.tb00108.x

Geena Davis Institute on Gender in Media. (2016). The reel truth: Women aren't seen or heard. An automated analysis of gender representation in popular films. Retrieved from https://seejane.org/wp-content/uploads/gdiq-reel-truthwomen-arent-seen-or-heard-automated-analysis.pdf

Gerbner, G. (1998). Cultivation analysis: An overview. Mass Communication and Society, 1, 175-194. https://doi.org/10.1080/15205436.1998.9677855

Götz, M., \& Lemish, D. (2012). Gender representations in children's television worldwide: A comparative study of 24 countries. In. M. Götz \& D. Lemish (Eds.), Sexy girls, heroes, and funny losers: Gender representations in children's TV around the world (pp. 9-48). Frankfurt: Peter Lang. https://doi.org/10.3726/978-3-653-01426-6 
Götz, M., Hofmann, O., Brosius, H. B., Carter, C., Chan, K., Donald, St. H. ... Zhang, H. (2008). Gender in children's television worldwide: Results from a media analysis in 24 countries. TELEVIZION, 21, 4-9.

Grabe, S., \& Hyde, J. S. (2009). Body objectification, MTV, and psychological outcomes among female adolescents. Journal of Applied Social Psychology, 39, 2840-2858. https://doi.org/10.1111/j.1559-1816.2009.00552.x

Halim, M. L., \& Lindner, N. (2013). Gender self-socialization in early childhood. In R. E. Tremblay, M. Boivin, \& R. D. Peters (Eds.). Encyclopedia on Early Childhood Development [online], 1-6. Montreal, Quebec: Centre of Excellence for Early Childhood Development and Strategic Knowledge Cluster on Early Childhood Development. Retrieved from http://www.child-encyclopedia.com/documents/Halim-LindnerANGxp1.pdf

Halim, M. L., Ruble, D. N., Tamis-LeMonda, C. S., Zosuls, K. M., Lurye, L. E., \& Greulich, F. K. (2014). The case of the Pink Frilly Dress and the avoidance of all things "girly": Children's appearance rigidity and cognitive theories of gender development. Developmental Psychology, 50, 1091-1101. https://doi.org/10.1037/a0034906

Hoffner, C. (1996). Children's wishful identification and parasocial interaction with favorite television characters. Journal of Broadcasting \& Electronic Media, 40, 389-402. https://doi.org/10.1080/08838159609364360

Hoffner, C., \& Buchanan, M. (2009). Young adults' wishful identification with television characters: The role of perceived similarity with characters attributes. Media Psychology, 7, 325-351.https://doi.org/10.1207/S1532785XMEP0704_2

Johnson, F., \& Young, K. (2002). Gendered voices in children's television advertising. Critical Studies in Media Communication, 19, 461-480. https://doi.org/10.1080/07393180216572

Jones, J. (2011). Gender and racial representations on children's Saturday morning cartoons. California State University, Fullerton.

Kohn, E. (2013). 'Adventure Time' writer Rebecca Sugar on 'Steven Universe,' being Cartoon Networks first female show creator and why pop art is 'offensive.'IndieWire. Retrieved from https://www.indiewire.com/2013/11/adventure-time-writer-rebecca-sugar-on-steven-universe-being-cartoonnetworks-first-female-show-creator-and-why-pop-art-is-offensive-33362/

Koo, T. K., \& Lo, M. Y. (2016). A guideline for selecting and reporting intraclass correlation coefficients for reliability research. Journal of Chiropractic Medicine, 15, 155-13. https://doi.org/10.1016/j.jcm.2016.02.012

Landers, R. N. (2015). Computing intraclass correlations (ICC) as estimates of interrater reliability in SPSS. The Winnower, 2, e143518.81744. https://doi.org/10.15200/winn.143518.81744

Leaper, C., Breed, L., Hoffman, L., \& Perlman, C. A. (2002). Variations in the Gender-Stereotyped Content of Children's Television Cartoons Across Genres. Journal of Applied Social Psychology, 32, 1653-1662. https://doi.org/10.1111/j.1559-1816.2002.tb02767.x

Lemish, D., \& Rice, M. L. (1986). Television as a talking picture book: A prop for language acquisition. Journal of Child Language, 13, 251-274. https://doi.org/10.1017/S0305000900008047

Linebarger, D. L., \& Walker, D. (2005). Infants' and toddlers' television viewing and language outcomes. American Behavioral Scientist, 48, 624-645. https://doi.org/10.1177/0002764204271505

Lovelace, V., Scheiner, S., Dollberg, S., Segui, I., \& Black, T. (1994). Making a neighbourhood the Sesame Street way: Developing a methodology to evaluate children's understanding of race. Journal of Educational Television, 20, 6978. https://doi.org/10.1080/0260741940200202

Markman, E. R. (2011). Gender identity disorder, the gender binary, and transgender oppression: Implications for ethical social work. Smith College Studies in Social Work, 81, 314-327. https://doi.org/10.1080/00377317.2011.616839

Martin, C. L., \& Halverson, C. F. (1981). A schematic processing model of sex typing and stereotyping in children. Child Development, 52, 1119-1134. https://doi.org/10.2307/1129498

Martinez, R. (2015, November 12). Fabulously fiendish: Disney villains and queer-coding. Quail Bell Magazine. Retrieved from http://www.quailbellmagazine.com/the-real/social-issues-queerness-and-media-representation

Martins, N., \& Harrison, K. (2012). Racial and gender differences in the relationship between children's television use and self-esteem: A longitudinal study. Communication Research, 39, 338-357. https://doi.org/10.1177/0093650211401376

Murnen, S., Greenfield, C., Younger, A., \& Boyd, H. (2016). Boys act and girls appear: A content analysis of gender stereotypes associated with characters in children's popular culture. Sex Roles, 74, 78-91. https://doi.org/10.1007/s11199-015-0558-x

Myers, K. (2012). “Cowboy Up!”: Non-hegemonic representations of masculinity in children's television programming. 
The Journal of Men's Studies, 20, 125-143. https://doi.org/10.3149/jms.2002.125

Nathanson, A., Wilson, B., McGee, J., \& Sebastian, M. (2002). Counteracting the effects of female stereotypes on television via active mediation. Journal of Communication, 52, 922-937. https://doi.org/10.1111/j.14602466.2002.tb02581.x

Olson, K. R., \& Gülgöz, S. (2018). Early findings from the TransYouth Project: Gender development in transgender children. Child Development Perspectives, 12, 93-97. https://doi.org/10.1111/cdep.12268

Olson, K. R., Durwood, L., DeMeules, M., \& McLaughlin, K. A. (2016). Mental health of transgender children who are supported in their identities. Pediatrics, 137, 1-10. https://doi.org/10.1542/peds.2015-3223

Olson, M. (2013). The Adventure Time encyclopaedia: Inhabitants, lore, spells, and ancient crypt warnings of the Land of Ooo circa 19.56 B.G.E- 501 A.G.E. New York, New York: Abrams Books.

Polo, S. (2016, May 11). Steven Universe, explained. Polygon. Retrieved from https:/www.polygon.com/tv/2016/5/11/11604098/steven-universe-explained

Puchner, L., Markowitz, L., \& Hedley, M. (2015). Critical media literacy and gender: Teaching middle school children about gender stereotypes and occupations. Journal of Media Literacy Education, 7, 23-34.

Rice, M. L., Huston, A. C., Truglio, R., \& Wright, J. (1990). Words from Sesame Street: Learning vocabulary while viewing. Developmental Psychology, 26, 421-428. https://doi.org/10.1037/0012-1649.26.3.421

Rude, M. (2018, August 2). How this nonbinary woman created the queerest cartoon on television. them. Retrieved from https://www.them.us/story/rebecca-sugar-steven-universe-interview

Ryan, E. L. (2010). Dora the Explorer: Empowering preschoolers, girls, and Latinas. Journal of Broadcasting \& Electronic Media, 54, 54-68. https://doi.org/10.1080/08838150903550394

Signorielli, N. (2012). Television's gender-role images and contribution to stereotyping. In Handbook of children and the media (2 ${ }^{\text {nd }}$ ed., pp 321-339). Los Angeles: Sage.

Smith, S. L., Choueiti, M., \& Pieper, K. (2016). Inclusion or invisibility? Comprehensive Annenberg report on diversity in entertainment. Retrieved from http://annenberg.usc.edu/research/aii/research/gender/

Stamou, A. G., Maroniti, K., \& Griva, E. (2015) Young children talk about their popular cartoon and TV heroes' speech styles: media reception and language attitudes, Language Awareness, $24, \quad 216-232$. https://doi.org/10.1080/09658416.2015.1075545

Thompson, T. L., \& Zerbinos, E. (1995). Gender roles in animated cartoons: Has the picture changed in 20 years? Sex Roles, 32, 651-673. https://doi.org/10.1007/BF01544217

Tiggemann, M., \& Slater, A. (2015). The role of self-objectification in the mental health of early adolescent girls: Predictors and consequences. Journal of Pediatric Psychology, 40, 404-8711. https://doi.org/10.1093/jpepsy/jsv021

Trekels, J., \& Eggermont, S. (2017). Beauty is good: The appearance culture, the internalization of appearance ideals, and dysfunctional beliefs among tweens. Human Communication Research, 43, 173-192. https://doi.org/10.1111/hcre.12100

Walsh, A. \& Leaper, C. (2020). A content analysis of gender representation in preschool television. Mass Communication and Society, 23, 331-355. https://doi.org/10.1080/15205436.2019.1664593

Ward, L. M., \& Aubrey, J. S. (2017). Watching gender: How stereotypes in movies and on TV impact kids' development. San Francisco, CA: Common Sense.

\section{Copyrights}

Copyright for this article is retained by the author(s), with first publication rights granted to the journal.

This is an open-access article distributed under the terms and conditions of the Creative Commons Attribution license which permits unrestricted use, distribution, and reproduction in any medium, provided the original work is properly cited. 